NEW LITERARIA-

An International Journal of Interdisciplinary Studies in Humanities

Volume 1, No. 2, November-December, 2020, PP 32-39

ISSN- 2582-7375

DOI: https://dx.doi.org/10.48189/nl.2020.v01i2.004

www.newliteraria.com

\title{
Towards a Postcolonial Pedagogy
}

\section{Durba Basu}

\begin{abstract}
The onslaught of COVID-19 has veritably turned the world upside down and has necessitated a shift away from in-class teaching worldwide. As teachers around the world, in various socio-economic contexts, negotiate on a daily basis, the challenges of shifting gear to 'remote'- teaching, it is pertinent to ask what the implications of this change are for any commitment to postcolonialism. If the object of pedagogy is to transform the student from object to subject, in Paulo Freire's classic formulation, how does the process play out under the current conditions of teaching and learning, which, it seems, are here to stay? I proceed on the basis of my experience of teaching English literature in a suburban campus in India, where, as it is, teachers operate within minimal infrastructure and must deal with varying levels of linguistic competence within the student body. What additional challenges are posed by online teaching in such a scenario? How can postcolonial analyses help uncover the stakes of teaching and learning in a suburban Indian context? What larger implications does this have for the teaching of literature in particular, and pedagogy in general? In other words, what does a thoroughgoing postcolonial pedagogy under these circumstances look like?
\end{abstract}

Keywords: Pedagogy, Literary pedagogy, Postcolonial pedagogy

\section{Introduction}

I proceed from the premise that postcolonialism is a way of thinking, an attitude that might be expressed not only in academic work, but in the way that it is carried out. The aspect of academic work I am specifically concerned with here is pedagogy: what, in the work I do, like a good many of my intended readers, may be called distinctively "postcolonial"? While thoroughgoing postcolonialism must necessarily flow into pedagogy at the level of praxis, I think the question of pedagogy is all the more pertinent now in the wake of COVID-19. The shift to 'remote instruction' necessitated the world over by the pandemic has meant teachers and students alike having to carry on their work while wrestling with unequal access to a variety of resources. My attempt will be to take on board this change particular to our times, alongside more general considerations. In other words, what might a postcolonial pedagogy look like, especially in the world after COVID-19? In beginning to think through this question, I will draw upon the work of the Brazilian educator and philosopher Paulo Freire (1921-1997), and also on my own experiences of literary pedagogy in various contexts.

What is exactly at stake in literary pedagogy at the periphery of the periphery? What are the hurdles, both for teacher and student, posed by a text such as Gayatri Chakravorty Spivak's translation of Mahasweta Devi's short-story "Draupadi?" 


\section{The Freirean schema: the 'banking concept of education', and 'problem-posing education'}

Freire's Pedagogy of the Oppressed, first published in 1973, is partly inspired by Frantz Fanon's The Wretched of the Earth. Fanon's formulation of the dichotomy between colonizer and colonized, and the broad problematic of translation that he propounds in both The Wretched of the Earth and Black Skins, White Masks, remains central to postcolonial studies, as pointed out by Robert Young (Young, 2003, p.144). As Young shows, if the process of colonization is a translation of the colonized from subject to object, all anticolonialism (and postcolonialism) is about a retranslation from objecthood to subjecthood.

Freire very helpfully describes the teacher-student relationship in the system of education he must reform as "narrative," in which the teacher is the narrator, the subject, and the student has no choice, but to remain as the passive receptacle, the object of the whole process. What is more, the teacher "expounds" on a topic that is totally unrelated to the "existential experience of the students," and effectively, their whole experience of the process of education is alienating (Freire, 2004, 71). Education, in this model becomes "an act of depositing," with the students being the depositories and the teacher being the depositor. The teacher does not communicate but "issues communiqués," and the deposits that the students receive are to be memorized and repeated (Freire, 2004, 72). In other words, what is taught in the classroom is to be remembered and reproduced, rather than its provoking any thought, let alone action or transformation. The Hegelian master-slave dialectic is repeated here with the exception, as Freire points out, that students never get to know that "they educate the teacher" (Freire, 2004, p. 72).

Freire posits that the "banking" concept of education is effectively a process of dehumanization. Dehumanization "marks not only those whose humanity has been stolen, but also (though in a different way) those who have stolen it" (Freire, 2004, p. 44). Freire further goes on to exhort that

In order for their struggle to have meaning, the oppressed must not, in seeking to regain their humanity (which is a way to create it), become in turn oppressors of the oppressors, but rather restorers of the humanity of both (Freire, 2004, p. 44).

Thus, the "banking" concept of education serves to dehumanize both teachers and students, while a liberatory pedagogy would be a transformative experience for both. After Freire, a liberatory pedagogy (or "problem-posing method" of education) can be practiced by a teacher only when she tries to communicate and not issue communiqués, that have to be memorized and regurgitated. Liberatory pedagogy, in contrast, makes the learner capable of thinking critically beyond the immediate subject matter that is being taught. The pedagogic process effects a transformation in both the teacher and the student, so that they become "teacher-student" and "student-teacher" respectively (Freire, 2004, p. 80). In other words, to liberate the student from oppression, the teacher has to "conscientize" the student, who first becomes aware of her oppression, and then begins to surmount it, and develops a "consciousness of consciousness of consciousness" (Freire, 2004, p. 79).

A truly emancipatory pedagogy, after Freire, is thus one that is dialogic. It is an exchange that edifies both parties, rather than a one-way transference of what the teacher decides is "essential information," and is therefore a process in which both teacher and student are eventually transformed. To put it another way, teacher and student are translated 
Towards a Postcolonial Pedagogy

into "teacher-student" and "student-teacher."

\subsection{The possibility of a postcolonial pedagogy}

Implicit in my contention is that inasmuch as a pedagogic practice endeavours to empower the student beyond the simple goal of transferring valued or even privileged information, it can be construed as an instance of postcolonial pedagogy. To empower is to translate from objecthood to subjecthood, in the Fanonian sense (see section 1). In the pedagogic situation, to empower is to induct the student as an equal participant into the realm of knowledge. While this may be the goal of effective pedagogy in a general sense, what I want to focus on specifically is the pedagogic predicament of the postcolonialist in the periphery of the periphery in the Anglophone world.

\section{Teaching Mahasweta Devi's "Draupadi" in translation in "other" places}

A hundred and forty kilometers from Kolkata, in the heart of rural Purba Medinipur, at the end of the second decade of the twenty-first century, I find the basic ways in which we contextualize texts in literary studies proving inadequate, even obfuscatory, for my pedagogic purposes. Let me elaborate.

The young men and women I encounter in classrooms here daily are impressionable, sensitive, and "curious" in the Arnoldian sense (Arnold, 1993, pp.58-9). Most of them want to enter various services right after college, and a few, to pursue postgraduate studies before working. For some of the women students, wanting to study further or work is nothing short of a rebellion, and more often than not, it is a dream nurtured with the silent support of their mothers, who are without exception homemakers. Like the vast majority of literary undergraduate classrooms in India, linguistic competence in these classrooms is most usually limited, and in this instance, uneven as well. Knowing this, it is impossible to keep to English as the only medium without a kind of bad faith. A bilingual medium of teaching literature in English, then, becomes necessary in this context for the sake of clarity. I have denoted this pedagogic space as "other" in the section-heading for these reasons. I have to completely overlook deficiencies of linguistic competence, and must find ways to work around the problem, which includes occasionally taking on the role of a language-teacher.

The college library does have resources, even if limited, for meeting the needs of students for both language-learning and background reading required for literary studies, which I do guide them to, but there are impediments galore on their path. My students cycle to college and back home every day, and on an average, a one-way ride takes them forty-five minutes to one-hour, and handling their part of household chores also involves long rides to secure provisions. Most, if not all, are first-generation college-goers. Evidently, for most of these young men and women, often sensitive though not equally expressive, a life devoted to the literary studies is too much of a luxury. It begins to seem to me, it is necessary to impart to them according to their propensities, within my teaching of literature, competences (most usually linguistic competences, verbal and non-verbal) they may find useful and such as I am able to transfer.

In order to contextualize a text, one of the more effective pedagogic strategies seems to be to bring alive the context with the help of Bangla, ${ }^{1}$ the other language I share with my students. This, even if it makes the material somewhat accessible, does not of course solve

\footnotetext{
'I use the word 'Bangla' to denote the language instead of the anglicized spelling 'Bengali', the word being a colonial hang over, that could be used substantively to denote the language, or adjectivally to denote the speakers of the language.
} 
the problem of the required background reading that a "standard" literary training necessarily involves. Under these circumstances then, what particular difficulties does a text such as "Draupadi" pose?

\section{1. "Apprehending" Dopdi/Draupadi}

Read in the academia in the translation by Gayatri Chakravorty Spivak, "Draupadi" is a quintessentially postcolonial text. Reading both the Bangla text and the translation, we find Spivak has evidently devised an optic of translation for rendering Mahasweta Devi's palimpsestic language, in which the degrees of lexicalization of terms originally belonging to the colonizer's language reveal degrees of colonial remains and neocolonial complicity. In her translation, she italicizes the words that appear in Roman script in Mahasweta Devi's text. As Spivak points out in the translator's foreword, all words associated with armed combat originate in the colonizer's language (and are therefore italicized in her translation), and despite having no knowledge of English, Dopdi is able to wield these terms in a manner that serves to intimidate Senanayak (Spivak, 2006, p. 255).

Part of the challenge of reading this text arises from Dopdi's remoteness from my quotidian experience as a middle-class Indian woman academic, a gap which no amount of empathy would perhaps be sufficient to bridge. Spivak points out early in her translator's foreword that the first-world academic is necessarily distant from Dopdi, and can at best arrive at Senanayak's "doublethink", his deep understanding of Dopdi resulting from his scholarly endeavours. In fact, Senanayak is optimally distant from the object of his inquiry, in the interest of the nation-state (and his own), which facilitates the fulfilment of its oppressive agenda (Spivak, 2006, p. 246). I would suggest that the third-world academic is similarly imbricated as well, even though Spivak directs her observations towards the first-world academic. The academic, though, is not directly part of the establishment in the way Senanayak is, and it follows that her implication in Dopdi's fate cannot be identical, but this issue demands separate discussion, and is beyond the scope of this paper. I will return to the idea of the gap, therefore, for this is also from where the difficulties of teaching the text arise, and not just because I feel there is an unbridgeable gulf between me and Dopdi: nothing in my students' experience of life or literature has prepared them for a character like her.

Any suggestions of the colonial relationship that obtains between the nation-state and certain regions of the nation, or certain sections of the population like the santals, in this case, become difficult for my students to comprehend. This is not to suggest, of course, that these or other complexities may not arise in teaching this text at other sites. At the metropole, where one may expect higher linguistic competence in the student body, the need for annotations of context will be greater in some ways. My object in denoting the site of my reflections as "other" is to signify a site in which certain usual expectations of competence in the student body, and availability of academic resources cannot be assumed as given, which makes this site even more peripheral to the majority of Indian classrooms. At the same time, the site of my pedagogic practice also enables me to utilize certain cultural resources not usually thought of as teaching resources, and to these I will return.

Whether one reads Mahasweta Devi's text or Spivak's translation, the language of Dopdi's songs poses unique difficulties. A certain amount of meaning remains fugitive, though Mahasweta Devi uses the register of Bangla that would be recognizable as "standard" to most contemporary readers of the language, and Spivak uses "standard" English defamiliarized occasionally by the italicization of words lexicalized into Bangla (which appear in Roman font in Mahasweta Devi's text) or the transcription of Dopdi's songs in Roman font. 
The Santali (also spelt as "Santhali") language is spoken in parts of the neighbouring districts of Paschim Medinipur and Jhargram, which along with Purba Medinipur constituted the district of Medinipur not very long ago, before they were split for administrative convenience. The historical distantiation of the Santal people has meant that although my students have grown up in relative geographical proximity, they have no chance of knowing even a smattering of Santali. Santali departments do exist in various universities in West Bengal, but the study of Santali language and literature remains largely academic, and pursued mostly by those who identify as Santals. Ironically (like Senanayak), I stand a greater chance of getting to learn Santali by virtue of academic contacts.

\subsection{Contextualizing "Draupadi" in the time of COVID-19}

Dopdi Mejhen's life of fleeing the police and army arouses the interest and sympathy of my students, but Spivak's extensive discussion of the context of the story in her foreword is beyond their linguistic competence. The theoretical terms she invokes would require annotation in classrooms anywhere, and my classroom is no exception, but even the concise history of the Naxalite movement that she provides needs quite a lot of explication. Add to this the constraints and vagaries of online teaching. Online teaching in the time of the pandemic has meant for me resorting to the asynchronous mode, sharing audio lectures and other files via Google drive and WhatsApp, as the unsteady connectivity of my students does not permit smooth web-conferencing. Any live two-way discussion to get a sense of what they are making of the material I am sending them is only possible by means of conference calling by telephone. Their problems are multifarious: not everyone has access to a smartphone throughout the day, and staying at home, especially for the women students, means having to take on a greater share of household chores than they would before lockdown. It is indeed a bit of luck that all students in my department barring one, has access to a smartphone for at least some part of the day to be able to go through all the teachinglearning material sent by teachers.

As a standard procedure, if I teach any text that has been translated from Bangla, I insist that students make the fullest use of their linguistic competence and read the Bangla text too, and there is no exception in this case. This not only facilitates their reading of the "difficult English text" but allows me to broach, even if briefly, certain aspects of translation.

Beyond what I offer by way of explaining the context of the story, and what they may make of the foreword after my encouragement to perform a directed reading of certain passages, I send them audios of two of Kabir Suman's ${ }^{2}$ songs, as their mobile data connectivity allows them to play audio files smoothly (as well as watch YouTube), even if it is not suitable for videoconferencing. The songs by Kabir Suman that I send them encapsulate the history of the Naxalite movement. The effect is electric. This is a sort of teaching by proxy, by getting the song to do the some of the work of teaching. Bonduk nile haate, at the verbal level, narrates the history of the post-independence India and the debates

\footnotetext{
${ }^{2}$ Kabir Suman (b.1949) is a singer-songwriter, journalist, occasional actor and former Member of Parliament. The songs I refer to are titled Bonduk nile haate (also referred to by the first line of the song, as Kichhui poreni paate tai bonduk nile haate), and Chhatradharer gaan. Suman's oeuvre is marked by his eclecticism. With a wide variety of training, he draws on various musical traditions ranging from Indian classical, folk music, western classical, jazz, blues, rock and pop. The music of Chhatradharer gaan is inspired to some extent by Leonard Cohen's "The Partisan," which has for its theme the French Resistance in World War II, and was adapted by the lyricist Hy Zaret from $L a$ complainte du partisan (lyrics by the French Resistance leader Emmanuel d'Astier de la Vigerie, composed by Anna Marly).The song has been performed by many distinguished singers including Joan Baez and Esther Ofarim, but it is Cohen's version with which Suman's composition has more direct kinship.
} 
around development and modernization, activities resulting from which in the mineral-rich areas especially of erstwhile Bihar, Orissa and Andhra Pradesh, directly (and often, adversely) affect the lives of the different tribes that inhabit these areas. Chhatradharer gaan is a tribute to the Naxalite leader Chhatradhar Mahato, and while it is specific to a context later than that in which "Draupadi" is situated, the lyrics capture the essence of guerilla movements, and the state's ways of countering them. Though perhaps most of the pedagogic work of two the tracks happen at the non-verbal level: Suman has crafted an incantatory rhythm for both songs, and like the classic protest song, they are sung with the minimalist guitar accompaniment. Both songs make use of incremental repetition (both verbally and musically) that is very signature, but more pertinently, in this context, lend a structure that functions as a mnemonic device. Suman crafts a rhythm in Chhatradharer gaan that works two ways: it mimes the steps of an army in pursuit making their way through the forest, and simultaneously conjures up the furtive caution of the guerillas, by virtue of the sonic palette he uses and the way he bends the rhythm, so to speak, in the parts on Chhatradhar. The parts of the song that narrate the ways of the army are sung in a more cut-and-dried manner, with the notes measured out to the meter, which has the effect of accentuating the impression of the routine movements of a contingent. Suman plays around with the rhythm in the parts narrated from the perspective of the guerillas so that there is an impression of overflow, the effect of a kind of musical enjambment, and liberation from the restrictions of the meter. The latter effect serves to bring alive Dopdi and Dulna's lives as runaways. Through this lively excess, as it were, we get the cue about narratorial sympathy. In other words, the listener's sympathies are manipulated by non-verbal elements as much by the explicit verbal elements.

The history of the Santals, like that of many other tribes, is most usually available in the oral tradition. They typically compose songs narrating significant events (Devi, $1993 / 1995$, p. xviii). It would have been ideal to have my students listen to songs composed by Santals (but then again, these would have been in the Santali language), for a greater sense of context, but Kabir Suman's songs do incorporate a narrative from the tribal perspective, or at least the closest the urban troubadour ${ }^{3}$ can take us to Dopdi and Dulna.

From the questions my students begin to ask later about the context of the story and about music, the genre of the protest song, and so on and so forth, I can tell that their curiosity has been stirred, which is all that I have striven for. I begin to hope that this will encourage their interest in other texts that they have to study in the course, that they will find connections between these texts. Given the constraints I have to operate in, my goals have to be requisitely modest. It is a pity that not all texts I teach can be supplemented in this way, and this prompts other reflections about the curriculum.

The use of musical resources to provide a sense of context seems to have been especially effective in my pedagogic site in that students have been able to accomplish the task of "background reading" alternatively. The use of the song audios has enabled me to surmount the problem of limited library resources (which have been rendered inaccessible under lockdown) as well as the constraints imposed on teacher-student interaction by remote teaching. The songs narrate the historical background in a much more compact way than any reading material I could ask them to refer to (a possibility ruled out by the limitations of their linguistic competence, even if suitable material could have been available in the college library or from my personal collection). The compulsion of asynchronous online teaching has

\footnotetext{
${ }^{3}$ Suman calls himself a naagorik kobiyaal (and also has a song titled as such), which I translate as "urban troubadour." One of the major genres in his body of work comprises songs that perform social commentary, and in this regard, Suman is profoundly influenced by Lalon Fakir (1774-1890), whose songs were informed by his rejection of all distinctions based on caste and creed.
} 
made it impossible to gauge students' understanding of in-class teaching by direct interaction, or observation of non-verbal reactions. The use of these resources, however, has evidently made the teaching-learning experience more dialogic, after Freire, in that it has provoked the curiosity of students, as I point out in section 2.2. To this extent, they have been "conscientized."

The efficacy of this tactic leads one to think if this is not also an effective way to teach this text, at the pedagogic site I have outlined, under "normal" conditions of teaching that prevailed before the advent of COVID-19. I can only answer in the affirmative, though I am unable to provide any comparative analysis as this is the first time I have taught this text. In any case, it seems to me there should be institutional support for the use of cultural resources not conventionally utilized as teaching resources. Apart from infrastructural facilities at the pedagogic site, syllabi must be made more context-sensitive so that such resources can be taken advantage of.

If resources in the regional language can be mobilized to effect greater intelligibility of a text, there is a strong argument to be made for syllabi to be framed accordingly. By "resources" I wish to denote various kinds of texts: literature that can be read, or aural or visual resources. Otherwise, the curriculum only becomes an instrument of alienating students from the object of study, and we risk perpetuating the "banking concept of education," after Freire. The "Choice-Based Credit System" that has been implemented across universities in India over the last few years has effected a uniformity of curriculum, which though it has its merits, assumes uniform conditions of teaching and learning across the country. As developments in translation studies have shown, the experience of reading literary works is determined by the specificities of the site they are read in. There can be a wide variance in the challenges faced in teaching the same text in metropole and periphery, as I have tried to demonstrate via the experience of teaching Mahasweta Devi's "Draupadi," a text that has by now, become a core text of postcolonial literature, since Spivak's translation of it in Critical Inquiry in 1981. And then, there is the periphery of the periphery. Fortunately, there are unique resources, as shown in section 2.2 above, that are available for teaching in the periphery, and it behooves us to create possibilities within the curriculum itself to take full advantage of such resources.

At the time of writing, there is no end in sight for the shift to "remote teaching" initiated worldwide by the pandemic. Universities across the globe are thinking in terms of a combination of in-class and remote-teaching for the future. In such a scenario, tailoring curricula according to local contexts would be even more pedagogically effective.

There is a growing body of literature produced in regional languages in India that is also available in English translation. Since this literature has already generated academic interest, it should be incorporated into university syllabi. While mastery in a discipline can be achieved only after being exposed to the core body texts and/or topics particular to it, framing of syllabi should also involve sensitivity to context. If the bywords of postcolonial pedagogy are subjecthood for the learner, and accessibility, then the possibilities for both must be embedded within the curriculum at the very outset.

\section{Acknowledgments}

Grateful thanks to Ben Conisbee Baer for helping me trace the bibliographic information from continents away in the midst of the pandemic. I was initiated into Paulo Freire's thought during my $\mathrm{PhD}$ coursework at New York University, facilitated by the Henry M. MacCracken Fellowship. I would like to thank all my teachers, and all my students, in various parts of the world, too numerous to name individually, for all that they have taught 
me about pedagogy. I would also like to thank my parents, who are themselves teachers, and my first teachers of everything.

\section{References}

Arnold, Matthew. (1993). Culture and Anarchy and Other Writings. S. Collini (Ed.). Cambridge University Press.

Devi, Mahasweta. (2006) "Draupadi”. In Gayatri Chakravorty Spivak (Trans.), In Other Worlds: Essays in Cultural Politics. Routledge.

--. (1995). Interview taken December 1991. In Gayatri Chakravorty Spivak (Trans.), Imaginary Maps: Three Stories by Mahasweta Devi. Routledge. (Original work published 1993)

Fanon, Frantz. (1969). The Wretched of the Earth. (Trans.) Constance Farrington. Grove Press.

--. (2004). The Wretched of the Earth. Trans. Richard Philcox. New York: Grove Press. Freire, Paulo. (2006). Pedagogy of the Oppressed. New York: Continuum Books.

Spivak, Gayatri Chakravorty. (2006). In Other Worlds: Essays in Cultural Politics. Routledge.

Suman, Kabir. (2015, May 19). Chhatrodharer gaan [Video]. YouTube. https://www.youtube.com/watch?v=DBGokP1dhVc

--. (2013, December 26). Kichui Pore Ni Pate Tai Bonduk Nile Hate [Video]. YouTube. https://www.youtube.com/watch?v=cdvZS-IVIQQ

Young, Robert. (2003). Postcolonialism: A Very Short Introduction. Oxford University Press. --. (2001). Postcolonialism: An Historical Introduction. Malden, MA: Blackwell Publishing.

\section{Bio-note}

Dr Durba Basu earned her BA in English from Bethune College, University of Calcutta, her MA in English from Jadavpur University, and her PhD from New York University, USA. Her doctoral research dealt with linguistic issues in colonial Bengal. Her interests include postcolonial literatures and cultures, history of the book, modernisms and modernities, translation, and photography with an emphasis on South Asia. She knows seven languages, and is an active translator. Her English translation of one of Syed Mujtaba Ali's short stories is forthcoming from Jadavpur University Press. She has written and photographed for Jara Parijayee, a Bengali travel magazine. She reviews books for The Telegraph. She is Assistant Professor and Head, Department of English, Swarnamoyee Jogendranath Mahavidyalaya, an undergraduate college under Vidyasagar University, West Bengal.

Email: durba.basu@nyu.edu 